\title{
Readiness to Practise Social Work in Aotearoa New Zealand: Perceptions of students and educators
}

Liz Beddoe, Kathryn Hay, Jane Maidment, Neil Ballantyne and Shayne Walker

\begin{abstract}
The readiness to practice of newly qualified social workers in Aotearoa New Zealand is a contested subject. In recent years, criticism by public figures including government ministers and the New Zealand government appointed Children’s Commissioner have stimulated debate within the profession. Media critique of social work practice has highlighted many of the challenges faced by social workers. Significant policy developments, in particular a substantive government review of child protection services (Ministry of Social Development, 2015), have also increased the scrutiny of the capabilities of social workers.
\end{abstract}

A timely three-year multi-phase project 'Enhancing readiness to practise' is the first large study of social work education to be funded in Aotearoa New Zealand. The findings reported here have been derived from data collected in a series of focus group interviews with social work educators and students, in which they reflected on curricula in their programmes and explored their perceptions of readiness to practise. Overall, educators were positive about the preparedness of their graduating students but held concerns over the organisational environments they would enter. Students were more ambivalent about their readiness, but hopeful and committed to on-going learning.

Keywords: social work education, readiness to practice, Aotearoa New Zealand

\section{Introduction}

The readiness to practise of social workers entering the workforce is both topical and important. In Aotearoa New Zealand social work graduates seek employment in governmental and non-governmental organisations, as elsewhere working in highly complex practice circumstances, with some of the most vulnerable people in the community. Social 
workers have a significant role in supporting and advocating for clients, challenging social inequities and upholding principles of human rights and social justice (ANZASW, 2013).

In 2015 there were 3,885 social work students enrolled on recognised programmes within 17 different tertiary education institutions (TEIs) (five Universities; nine Polytechnics; two Wānanga (Māori higher education), and one Private Training Establishment. The Social Workers Registration Board (SWRB), as the social work regulator responsible for ensuring the safety of the public from social workers, monitors and recognises the TEI programmes for the purposes of registration (SWRB, 2016).

In addition to the SWRB, there are other stakeholders with a legitimate interest in the readiness of beginning social workers, including students; service users; the professional bodies, the Aotearoa New Zealand Association of Social Workers (ANZASW) and the Tangata Whenua Social Workers Association; large-scale employers of social workers (for instance, Ministry for Children Oranga Tamariki and District Health Boards; and nongovernment organisations that also employ graduate social workers.

The activity of social workers frequently attracts media, public and political attention and there is understandably considerable interest in the education and capabilities of social workers (Author, 2014; Taylor, \& Bogo, 2014). In the United Kingdom social work educators have played a leading role in researching workforce requirements (Moriarty \& Manthorpe, 2013, 2014) and designing outcome frameworks (Taylor \& Bogo, 2014; The College of Social Work, 2012) that may support the readiness to practise of new graduates. In Aotearoa New Zealand the readiness to practise of new graduates is under-researched and therefore it is timely to closely examine this area drawing on the perspectives of key stakeholders.

The readiness to practise of new graduates, and social workers generally, is sometimes questioned following high-profile incidents, for example child abuse tragedies, that have generated political pressure or questions of public trust in the people who have been working in the community with vulnerable people (Currer \& Atherton, 2008; Franklin, 2014; Harrison, Harries, \& Liddiard, 2014). In Aotearoa New Zealand the work of social workers has come under the media and political spotlights in recent times, usually after the deaths or injuries of children and young people who have had involvement with the former Child 
Youth and Family Services (now Ministry for Children Oranga Tamariki) (Author, 2014. Social work education has become increasingly targeted, primarily by politicians, as inadequately preparing social workers for practice (Author, 2014). This criticism was echoed by the Commissioner for Children in 2015 who questioned social work graduates' knowledge of family violence and their preparation for work in child welfare: "Currently," he told listeners, "you can graduate from a university with a bachelor degree in social work in New Zealand and know very little about child protection or domestic violence or the impact of abuse and neglect on a children's development ... That's not ok.” (Radio NZ, 2 April, 2015).

Since the passing of the Social Workers Registration Act 2003 the Aotearoa New Zealand social work curriculum has become more closely monitored and is now subject to a regular cycle of auditing and approval. While there is some flexibility for individual schools of social work to design and deliver their own curriculum, the SWRB Programme Standards must be met in order for the qualification to be recognised for registration purposes. The standards outline requirements associated with governance, curriculum, field education, admission criteria, professional and stakeholder collaboration and staff qualifications and resources (SWRB, 2016). Programmes must demonstrate how they will assess the SWRB core competencies needed for graduates to practise.

The findings reported in this article address a qualitative component of research conducted in the first phase of a three-phase mixed methods study. Two methods of data collection were used during the first phase of the study: documentary analysis of curriculum documents of all participating social work programmes, and focus group interviews with students and educators. Analysis of curriculum documents was used to create a hierarchical taxonomy called Topics for Indexing Social Work Education in Aotearoa New Zealand (TISWEANZ) (see Ballantyne et al. 2016 a, b, c for further information). The findings reported here are based on a series of focus groups with educators and students which were conducted over 2016-17.

\section{Literature}

Debates about social worker readiness to practice are found in much recent discussion of social work literature. Jack and Donnellan (2010) argue that qualifying education should be viewed as more of a foundation to continuing learning, rather than expecting graduates to be fully ready to practise when entering the workforce. Hussein, Moriarty, Stevens, Sharpe, and 
Manthorpe (2014) however, suggest that when challenges arise surrounding the performance of social workers, the quality of their qualifying education is called into question, often without any concomitant interrogation of how workforce experience may have impacted on the quality of their practice. Government responses often focus on greater control of tertiary curriculum, with conservative opinion favouring less emphasis on issues of social structure and more on knowledge and skills, focussed very narrowly on statutory social work at the expense of community work and other fields (Narey, 2014). This creates tensions between stakeholders, especially between government employers and regulators and social work educators (Rossiter, 2001; van Heugten, 2011).

Longstanding debates about the purpose of social work education have focused on whether the primary objective is to prepare social workers for working in specific practice settings, or with generic, transferable skills that they can adapt to changing clinical, political and organisational environments (Agllias, 2010; Moriarty, 2011). In the Aotearoa New Zealand context, the latter approach has been favoured within qualifying programmes emphasising a generic curriculum, which is not overly prescriptive (Beddoe, 2014). This is endorsed by the SWRB regulatory framework that approves these programmes to develop graduates ready for practise and with the competencies to enable professional registration (SWRB, 2016).

Education providers are thus expected to equip students so they can articulate core social work values, and possess foundational knowledge and skills (Frost, Höjer, \& Campanini, 2013) on which specialist skills can be built over exposure to social work practice. There are debates about whether social work curricula include the right balance of general and specific skills and knowledge training for future employment roles, especially for entering very demanding roles such as child welfare (Frost et al., 2013). It is generally held though that specialist training, for example in mental health or child protection, might be more appropriate as ongoing professional development (Staemphfli, Adshead, \& Fletcher, 2015). A perceived disparity between what is taught and the actual reality of practice raises further questions about whether social work curricula are 'fit for purpose' (Agllias, 2010; Wilson \& Kelly, 2010).

A good degree with quality placements can give confidence to students but does not necessarily prepare them fully for becoming an employee in a particular setting. The student role on placements does offer some protection, where workloads are managed and there is 
generally good oversight of students’ progress (Hay, Franklin, \& Hardyment, 2012; Seden \& McCormick, 2011; Walker, Crawford, \& Parker, 2008). Because there are safeguards in place, inappropriate expectations of student workload can be managed. Beyond this period expectations can be more problematic. The transition from being a student to being a new graduate can be very challenging.

Manthorpe, Harris, and Hussein (2012) have indicated inconsistent expectations between employers, educators and practitioners about what is essential content to ensure social work graduates are practice ready. In recent Scottish studies, Grant, Sheridan, and Webb (2014, 2017) found that social work qualifying education was generally seen to be appropriate and adequate in terms of preparing students for practising in the workforce. In a study in Aotearoa New Zealand agency managers highlighted preferences for specific attributes of social workers including flexibility, humility, confidence and resilience (Hay \& Brown, 2015). This raises questions as to how students' personal and interpersonal capabilities are nurtured or even assessed during their qualifying programme.

\section{A gap in the research}

Research to gather the views of students and educators about readiness to practice in Aotearoa New Zealand had not been undertaken, with most studies having focusing more on managers' and new graduates' perceptions. This current study, in its first phase, focuses on the on the current social work curriculum. Harden (2001) has argued that educators can think of the curriculum in three different ways: the planned curriculum (what is planned for learners), the delivered curriculum (what is delivered to learners) and the experienced curriculum (what is experienced by learners). While a taxonomy (TISWEANZ) and database that maps the curricula were developed to provide a snapshot in time of the current planned curriculum for social work in Aotearoa New Zealand, conducting focus groups with students and educators enabled us to explore perceptions of the taught and experienced curriculum.

In this article we focus primarily on educators' and final year students'” perceptions of readiness to practise. Focus groups with educators explored topics including social work pedagogy, issues currently confronting social work education in this country, curriculum content, identified gaps and beliefs about readiness to practise. Focus groups with students explored their opinions on the main curriculum areas and 'messages' in their programme, 
their perceptions of their readiness to practice and their views about gaps and limitations in their programmes.

\section{Method}

The first phase of the three-year study employed a mixed methods approach which offered a strong element of utility to the findings. Focus groups provided an opportunity to get closer to the lived experiences of senior students as well as social work educators. Engagement with these groups enabled a diversity of participant views to be accessed and for the findings to be enhanced and triangulated in the process of analysis (Bryman, 2012). It was the goal of this research process to access rich, comprehensive understanding of student and educator perceptions about the delivered curriculum. The interview questions were generated after consideration of the literature and feedback from a recent graduate and an educator so as to ensure suitability (Bryman, 2012).

Ethics approval was obtained from the University of Canterbury Ethics Committee for this part of the study. Confidentiality featured strongly in the ethical considerations for the design of the focus group interview recruitment procedures. Protection of confidentiality is further discussed below.

Students and educators from eight schools, selected from the 14 participating in the wider three-year study, were chosen to ensure geographical spread, type of TEI and student cohort size. The researchers approached the Head of School or delegate for each of the target schools to seek permission to have an email sent out to third and fourth year Bachelor of Social Work (BSW) students and final year qualifying masters students.

When administrators responded positively to this invitation, liaison was set up via the research assistant to establish a convenient date for the focus groups. After this step, a second email was sent to the programme's administrator for emailing out to the students and educators with an information sheet, consent form and focus group details. Potential participants could thus make direct email contact with the research assistant to signal their interest in being part of the focus group without their identity being revealed to the programme head or other staff. Interviews were conducted by a researcher not associated with the participants’ programme. 
The focus groups were 60-90 minutes in duration and were audio-recorded. Because of timing problems for various cohorts some students and one staff member were interviewed via telephone or Skype ${ }^{\mathrm{TM}}$. Interviews were transcribed and then de-identified by the researcher who conducted the interview in order to maximise privacy. The semi-structured group discussions were guided by the set of questions. All the authors facilitated focus groups. While this was practical for cost and logistical reasons, it did mean that questions were asked in a variety of ways and so the focus groups were perhaps more idiosyncratic than if only one researcher had been involved.

The focus group data were analysed using general thematic analysis, driven mainly by the questions in the first instance. One researcher coded all the transcripts using NVivo $11^{\mathrm{TM}}$ to manage the data and facilitate production of node reports, mainly coded to the specific questions addressed in all interviews. The node reports were thereafter analysed by two different researchers. Having determined the significant themes, some concepts were reexamined across the data set as a whole and further analyses will be conducted in due course.

\section{Participants}

Twenty-seven social work educators participated over the period November 2016 - February 2017. Educators taught across metropolitan and regional institutions, universities and polytechnics, in both islands. The participants were mainly aged between 40-60 and were predominantly Pākehā (white European), with four identifying as Pasifika and two as Māori. Ethnicity was not stated by two participants. They ranged from being new academics with one or two years' experience, to those with 30 years in education. The range of teaching subjects was well represented. While the BSW was the main degree taught, nine educators taught on qualifying masters programmes and some also engaged in postgraduate research supervision and teaching.

Thirty-five students participated in focus group or individual interviews over the period November 2016 - February 2017. Students were enrolled across metropolitan and regional institutions, universities and polytechnics, in both islands. The students were predominantly enrolled in BSW degrees, with only two in qualifying master's degrees. Most were full time students who were at the end of year 3 or 4 of a BSW or year 2 of a qualifying master's degree. 
Demographic data about participants is reported in a manner designed to assure anonymity. Participants are labelled by an alphanumeric code; the educator and student codes are not matched. The neutral pronoun 'they' is used.

\section{Findings}

The discussion with students and educators enabled the researchers to gain some views on readiness to practise prior to completion of their qualification. Both students and educators were generally positive about readiness to practise, with some considerable ambivalence about whether new graduates should be expected to be entirely ready. Caveats were suggested by both groups and these concerns mainly coalesced around the complex and pressured environment of social services, varying feelings of confidence and self-doubt, and the need for good support and ongoing learning once in the workforce. Both students and educators commented on entry to practice as an ongoing learning journey that might be challenged by employers' expectations.

\section{Agency environments}

Overall, students felt cautiously ready for practice with some trepidation about whether they would be able to meet the needs of a new agency and its service users. Students valued the skills they had to seek out information when faced with new challenges and attributed this to their confidence about their readiness. Student F1 captured very well the mixed feelings of final year students as they face moving into employment. Confidence is expressed as being ready to face the known environment, of where they have had their placements, but apprehension is felt about approaching a new setting, where they might be more exposed.

I don't think that you'd ever feel completely prepared going into a brand-new role. To walk into either of the placements I've just had, I'd feel completely competent and completely confident but I think there's something about going into a new agency as a brand new social worker and taking that student label off that's daunting but I think the experience that I've had this year, in trusting what I know and trusting what I've learnt has helped me to kind of...not fake it till you make it...but bluff my way through those first few months if I need to and learn about the environment that I'm going to be working in. So yeah, I feel competent but I think it's still a little bit daunting. Or terrifying. (Student F1)

Fears were also expressed about the environment in social work agencies: 
I think what concerns me is not so much the actual job, it's the political environment that we live in ... that's what concerns me and that's what fills me full of doubt. I can see the job of a social worker is something that I could do but I don't know about this current environment that we're in, this sort of targeting, needs-based, government that we've got at the moment. (Student I2)

Students anticipated a challenging environment where their ability to stick to their values would be tested:

I just think the structural causes of everything are just totally denied all the time really and it's all very well to blame social workers for not doing a good job but I mean how can you give power to people when they haven't even got enough food to eat or they haven't got a house to live in. (Student I 3)

Student $\mathrm{H} 2$ worried about the challenges being too great and thought they would have to remember their particular responsibilities in the role: 'you really have got to stick to it'. Giving up was an unattractive choice for this student who felt that giving up was unpalatable:

up feeling like there's no other option for you or for your clients, you know, like I've seen a lot lately with agencies and services in our community here that are just blatantly I guess giving up on these young people because they've done a lot wrong. (Student H2)

Confidence, doubts and fears

Students were largely positive about being ready to get out into the world of practice.

Confidence was defined by a mix of personal attributes - maturity, 'personality' values and experience:

I'm fine. But I'm nearly 48. I was ready to do that before I did the degree but I would have been totally dangerous, but yeah, I feel all good. (Student B1)

I personally am ready to get out there. I'm quite confident that what I lack in knowledge my personality makes up for. I would like to see if that way. (Student E3)

I think because I had part time jobs and, you know, picked different things up where I could expand on my knowledge and skills then I would definitely be ready. (Student G3)

Educators valued the students' ability to be open to learning, to use their critical thinking skills and to be adaptable: 
I guess readiness is only defined by the situation that you are presented with isn't it. I mean a lot of them will say no they are not ready because they are not confident. I guess [our job]is to encourage them to be confident and be open to learning and be critical are really. The rest will just come with good supervision and support. (Educator C2).

I think one of the key opponents of graduate preparation is a confidence that they gain through strategic thinking and critical analysis of what they have learnt and therefore are able to adapt that to wherever they go and thinking the placements that they do hold anchor some of those things and they seem to find their feet really quickly. (Educator J1)

Several students felt ready but acknowledged that they had doubts and were nervous about what was ahead. Student I1 expressed the ambivalence clearly: 'Sometimes I do, today I don't but sometimes I feel I've been well prepared. But some days I don't so I'm sort of plagued with self-doubt really'. And Student D1 relied on feedback gained in placement to boost confidence:

I feel as well prepared as I can I guess. It's always nerve-wracking doing these things after studying it for four years. I guess I always doubt myself but I just have to take on the feedback from my placement supervisor and be more confident within myself. I think I have the knowledge and skills to practice because the degree has really prepared me in that way. (Student D1)

Educators' doubts were about the lack of exposure to the work of practice. Having a clear framework for practice and a good sense of how to operate in the practice environment were seen as vital. Educator C1 felt that graduates needed to understand the nature of their employing organisations and how they might address concerns about practice:

when it's safe to react and when it's not, ...really getting their ducks in a row and knowing if the agency is practising unethically... to have some kind of skills under their belt that they can address either through [improving practice] in that agency or through criticising and moving on.... Because I know social workers who walked out of the job and by walking out they made a difference. (Educator C1)

Students and educators had shared concerns about the political and environments of practice. Educator G3 asked the question 'prepared like for what?' because if social work agencies were chaotic and demonstrating bad practice, 'then have we prepared our students for chaos and incompetence'. Students and educators shared this anxiety, fearing that they would encounter trouble if they felt the agency setting was incompatible with their values:

I'm absolutely terrified because I know how I operate and I'm a trouble maker... in my last job...I'm a trouble maker, I know where I... if the walk doesn't match the talk I will 
struggle in that environment, ... [because] I've seen workplaces crush people. (Student I2)

I think it puts our students in a difficult place because there are people like me who would spiel that kind of, I don't know, that idealism I guess and then they go into these real-world agencies which probably give a different message about social work and, you know, they’ve got to kind of grapple with [ that]. (Educator I4)

I've spent a lot of time over the past couple of months [in agencies] and you know, a lot of the social workers are just desperate because they're trying to empower people, which I think is a term that's totally overused ... because how can you empower people when there's nothing at the end of it, funding's been cut, there's no housing, people can't get better mentally or cure their addiction because... the basics aren't being met? (Student I2)

\section{A learning journey versus employers’ expectations}

Students who were close to finishing were starting to focus on employment:

I graduate next week so I'm, on the job hunt and it is something I've been thinking about quite a lot and I think, I do feel prepared, I feel more competent but ... social work roles can look so different depending on who you are and who you're working for and I think there's always going to be that length of time where you might feel a little bit out of your depth or you might not know how the processes work. (Student F1)

The student participants were remarkably consistent in their belief that graduating was the start of their lifelong learning in their social work career, therefore not the end of education but that their social work degree had instilled the basic foundations:

I think I've got the pathways to the different services sorted suddenly another pathway pops up, but I think that's on the job learning, but in terms of skills and theories and values and social policy and all those other learnings I think that's there already. (Student I1)

I feel quite prepared to practice social work; however, I do see that there is still so much more learning and growth for myself because I've only experienced working in social work on my placements. (Student B1)

Educators were clear that they wanted better support for graduates entering the workforce. This included building their confidence through good graduate supervision and induction support. Students were well prepared to ask for and expect to have quality supervision:

I am very much in favour of protected first years of practice while ideally 18 months to 2 years, but let's just go for one, where there are further learning opportunities, 
excellent supervision, protected workloads and those sorts of things that would just give people the opportunity to consolidate their degree learning into a particular field.

(Educator H2)

There should be a proper transition process from university to being a professional, I think. And the university and the employers need to have some sort of benchmarks around that. I think, that is probably the support for graduates is one issue, or one area around readiness for practise. (Educator D3).

An educator from the same institution, which had carried out some research on their graduates perceived confidence noted that after two or three years in practice graduate confidence had actually dropped: 'So, that is an interesting comment I suppose on how well supported they have been in the profession, or not'. (Educator D1).

Both educators and students expressed concern about employer expectations that new graduates would be competent and confident in all fields of practice. Both were clear that social work is so diverse that it was not possible to know everything across the sector. Students found this an additional pressure: 'there seems to be all of that negative stuff in the media that they're expecting us to be specialists straight away'. (Student J2). Educator C2 hoped that more employers would nurture new graduates rather than 'breaking them within 18 months by giving them high caseloads and lack of training and high expectations’. Educators were clear that it was not the role of generic social work programmes to prepare graduates to be work ready for a specific field of practice at a professional level: 'we don't gear our graduates to be able to be child protection [workers], or mental health practitioners' Educator B1). Placements were important in the preparation for practice in some fields however it was more important to spend classroom time 'preparing people to be critical in their approach and to learn well' (Educator B1).

\section{Discussion and conclusions: what needs to change?}

The findings of this qualitative study revealed ambivalence in both final year students and their educators about their readiness to practise. For both groups of participants concerns coalesced around the complexity of the societal milieu in which practice occurs and the immediate practice environment. Educators and students reported concerns about community levels of poverty, housing insecurity and the complexity of supporting service users with multiple complex issues. On top of this educators and students were worried about the resources and climate in the organisations where new graduates would seek employment. 
High case load numbers, stretched agencies, unreasonable targets all created doubt about whether there would be sufficient support for new graduates. The doubts expressed by students about their transition from protected student to worker echoes concern that the transition to being an employee can be quite shocking, as new graduates become exposed to a higher and more complex workload over time (Hay, Franklin, \& Hardyment, 2012).

Student life offers considerable flexibility and the supports offered by tertiary staff are no longer available to new practitioners (Hay, et al., 2012). The concerns of educators in this study were tempered by their strong belief that they had given their students tools to use in practice to mitigate the stress of multiple demands. However, both groups were aware there would be increased pressure on new graduates to manage multiple tasks and perform as an employee, rather than in the more protected student role (Seden \& McCormick, 2011; Walker, Crawford, \& Parker, 2008). Educators emphasised the importance of employers seeing new graduates as just that and not expecting them to know everything, especially in an unfamiliar field of practice. An improved understanding in the workforce that TEIs offer a generic qualifying programme was felt to be significant to both appropriate expectations regarding specialist knowledge and skills, and better support for beginning practitioners.

There is a clear indication that, while doubts and fears in those reaching the end of their qualifying education are not unexpected, the profession in Aotearoa New Zealand should explore the benefits that could be afforded in a programme to support new graduates. Support to assist to bridge the transition from protected student to fully engaged social worker is suggested. There are various models in which such support can be offered. The Assessed and Supported Year in Employment in England has been noted earlier as an example of a programme that significantly assists the professional development of newly qualified social workers' (NQSW) capabilities. During the programme managers are able to allocate fewer cases to NQSWs compared to those who have been practising for some time. Furthermore, less complex cases are expected to be assigned to the NQSWs, although due to the unpredictability of social work, sometimes the allocated workload may be more challenging than expected (Hussein et al., 2014). Additionally, a post-qualifying framework could be adopted to provide the ongoing specialist training needed in specialist fields of practice, such as child protection and mental health. 
The next phase of this study will survey how newly qualified social workers believe they are faring in the first two years of practice, and the perceptions of their managers. In the interests of sustainable workforce recruitment and retention of social workers in Aotearoa New Zealand, it is crucial for the profession to develop ways to both nurture and support the professional development of its newly-qualified and inexperienced practitioners.

Funding: This project was funded by a National Project Grant, Ako Aotearoa.

\section{References}

Agllias, K. (2010). Student to practitioner: A study of preparedness for social work practice. Australian Social Work, 63(3), 345-360.

Aotearoa New Zealand Association of Social Workers. (2013). Code of Ethics and Bicultural Code of Practice. Retrieved from http://anzasw.nz/wp-content/uploads/Code-ofEthics.pdf

Ballantyne, N., Beddoe, L., Hay, K., Maidment, J., Ngan, L., \& Walker, S. (2016). Technical report one: Methods for the creation of terms for indexing social work education in Aotearoa New Zealand). Retrieved from https://akoaotearoa.ac.nz/node/12658/files/

Ballantyne, N., Beddoe, L., Hay, K., Maidment, J., Ngan, L. \& Walker, S. (2016a). Technical report two: Analysis of curriculum documents. Retrieved from https://akoaotearoa.ac.nz/node/12658/files/

Ballantyne, N., Beddoe, L., Hay, K., Maidment, J., Ngan, L., \& Walker, S. (2016b). Technical report three: TISWEANZ taxonomy. Retrieved from https://akoaotearoa.ac.nz/node/12658/files/

Beddoe, L. (2014). A matter of degrees: The role of education in the professionalisation journey of social work in New Zealand. Aotearoa New Zealand Social Work, 26(2/3), $17-28$.

Bryman, A. (2012). Social research methods (4th ed.). Oxford UK: Oxford University Press.

Currer, C., \& Atherton, K. (2008). Suitable to remain a student social worker? Decision making in relation to termination or training. Social Work Education, 27(3), 279-292. doi: 10.1080/02615470701381343 
Franklin, B. (2014). Citizen journalists or cyber bigots? Child abuse, the media and the possibilities for public conversation. In S. Wagg \& J. Pilcher (Eds.), Thatcher's grandchildren? Politics and childhood in the twenty-first century (pp. 27-44). Basingstoke: Palgrave Macmillan.

Frost, E., Höjer, S., \& Campanini, A. (2013). Readiness for practice: Social work students' perspectives in England, Italy, and Sweden. European Journal of Social Work, 16(3), 327-343. doi: 10.1080/13691457.2012.716397

Grant, S., Sheridan, L., \& Webb, S. A. (2014). Evaluation study for the Scottish social services council (SSSC): Readiness for practice of newly qualified social workers. Glasgow, Scotland: Glasgow Caledonian University.

Grant, S., Sheridan, L., \& Webb, S. A. (2017). Newly qualified social workers' readiness for practice in Scotland. British Journal of Social Work, 47, 487-508. doi: 10.1093/bjsw/bcv146

Harden, R. M. (2001). AMEE Guide No. 21: Curriculum mapping: a tool for transparent and authentic teaching and learning. Medical Teacher, 23(2), 123-137. doi:10.1080/01421590120036547

Harrison, C., Harries, M., \& Liddiard, M. (2014). The perfect storm: Politics, media and child welfare policy making. Communities, Children and Families Australia, 8(2), 29-45.

Hay, K., Franklin, L., \& Hardyment, A. (2012). From student to employee: A conversation about transition and readiness for practice in a statutory social work organisation. Social Work Now, 50, 2-9.

Hay, K., \& Brown, K. (2015). Social work practice placements in Aotearoa New Zealand: Agency managers’ perspectives. Social Work Education, 34(6), 700-715. doi: $10.1080 / 02615479.2015 .1062856$

Hussein, S., Moriarty, J., Stevens, M., Sharpe, E., \& Manthorpe, J. (2014). Organisational factors, job satisfaction and intention to leave among newly qualified social workers in England. Social Work Education, 33(3), 381-396.

Jack, G., \& Donnellan, H. (2010). Recognising the person within the developing professional: Tracking the early careers of newly qualified child care social workers in three local authorities in England. Social Work Education, 29(3), 305-318. 
Manthorpe, J., Harris, J., \& Hussein, S. (2012). Employers' experiences and views of grow your own social work programmes: A qualitative interview study. Social Work Education, 31(5), 637-650.

Manthorpe, J., Moriarty, J., Stevens, M., Hussein, S., \& Sharpe, E. (2014). The 'making' of social workers: Findings from interviews with managers of newly qualified social workers. Practice, 26(2), 97-111. doi: 10.1080/09503153.2013.867941

Ministry of Social Development (2015). Expert Panel final report: Investing in New Zealand's children and their families. Wellington, NZ: Author. Retrieved from https://www.msd.govt.nz/documents/about-msd-and-our-work/workprogrammes/investing-in-children/investing-in-children-report.pdf

Moriarty, J. (2011). Literature review for the curriculum development work stream. Social Care Workforce Research Unit. London: King’s College.

Moriarty, J. \& Manthorpe, J. (2013) Shared expectations? Reforming the social work qualifying curriculum in England, Social Work Education, 32(7), 841-853. doi: 10.1080/02615479.2012.723683

Moriarty, J. \& Manthorpe, J. (2014) Controversy in the curriculum: What do we know about the content of the social work qualifying curriculum in England? Social Work Education, 33(1), 77-90.

Narey, M. (2014). Making the education of social workers consistently effective: Report of Sir Martin Narey's independent review of the education of children's social workers Retrieved from https://www.gov.uk/government/publications/making-the-educationof-social-workers-consistently-effective

Rossiter, A. (2001). Innocence lost and suspicion found: Do we educate for or against social work. Critical Social Work, 2(1).

Seden, J. \& McCormick, M. (2011). Caring for yourself, being managed and professional development. In J. Seden, S. Matthews, M. McCormick, \& A. Morgan, Professional development in social work: Complex issues in practice. (pp. 171-177). Oxon: Routledge.

Social Workers Registration Board (2016). Continuing professional development http://www.swrb.govt.nz/already-registered/continuing-professional-development Wellington NZ: SWRB.

Social Workers Registration Board. (2016). Programme recognition standards. www.swrb.govt.nz/policy. Wellington NZ: SWRB. 
Staemphfli, A., Adshead, l., \& Fletcher, J. (2015). Ready for qualified practice? A comparative study of capability for critical reflection and analysis of MA social work and MA step up to social work students at the end of second placement. Social Work Education, 34(8), 952-966.

Taylor, I., \& Bogo, M. (2014). Perfect opportunity, perfect storm?: Raising the standards of social work education in England. British Journal of Social Work, 44, 1402-1418. doi:10.1093/bjsw/bct077

The College of Social Work (2012). Assessing practice using the professional capabilities framework. London: The College of Social Work. Retrieved from https://www.basw.co.uk/resources/tcsw/Assessing\%20practice\%20using\%20the\%20P CF\%20guidance.pdf

The College of Social Work. (2015). Review of the professional capabilities framework. London: The College of Social Work. Retrieved from https://www.basw.co.uk/pcf/pcfreview2015.pdf

van Heugten, K. (2011). Registration and social work education: A golden opportunity or a Trojan horse? Journal of Social Work, 11(2), 174-190. doi:10.1177/1468017310386695

Walker, K., Crawford, K. \& Parker, J. (2008). Practice education in social work: A handbook for practice teachers, assessors and educators. Exeter, UK: Learning Matters

Wilson, B., \& Kelly, G. (2010). Evaluating the effectiveness of social work education: Preparing students for practice learning. British Journal of Social Work, 40, 24312449. doi:10.1093/bjsw/bcq019 